\title{
SS-A (Ro) antibody in random mother-infant pairs
}

\author{
MICHAEL CALMES, BRUCE A BARTHOLOMEW \\ From the Texas Tech University Health Sciences Center, School of Medicine, Department of Internal \\ Medicine, Division of Rheumatology, Lubbock, Texas
}

SUMMARY In a study of the occurrence of detectable antibodies to SS-A and SS-B in 300 randomly selected mother-infant pairs, three $(1 \%)$ mother-infant pairs were positive for precipitating antibodies to SS-A. No matched pairs were positive for SS-B. Review of the clinical history of the mother-infant pairs with SS-A antibodies failed to reveal evidence of connective tissue disease or the neonatal lupus syndrome. Follow up of two of the three SS-A positive motherinfant pairs two months after delivery also showed no evidence of disease. While the SS-A antibody may be closely associated with the development of the neonatal lupus syndrome, our study does not support the proposed aetiological nature of the antibody. Random maternal screening for possible SS-A antibody positivity and potential neonatal lupus syndrome does not appear to be warranted.

Neonatal lupus syndrome occurs in infants within the first few months of life and is a transient phenomena. The most common clinical manifestations are erythema annulare centrifugum and congenital heart block. Other associated manifestations include lymphadenopathy, hepatosplenomegaly, and haematological abnormalities consisting of leucopenia, haemolytic anaemia, or thrombocytopenia ${ }^{1-13}$

The aetiology of the syndrome is unknown. It occurs in infants of mothers with symptomatic connective tissue disease and in infants of asymptomatic mothers with or without connective tissue disease. The SS-A (Ro) antibody has been found in infants with the neonatal lupus syndrome and it has been suggested that transplacental transfer of this antibody is a possible cause.

This study was undertaken to determine the incidence of detectable concentrations of SS-A antibodies in normal mothers and their newborn infants and the predictive value of this measurement for the development of the neonatal lupus syndrome.

\section{Patients and methods}

Blood samples were obtained by venepuncture from 300 randomly selected mothers in active labour admitted to labour and delivery during September and October 1983 and from the cords of their respective infants at the time of delivery. The

Accepted for publication 26 September 1984 patient population divided by ethnic group was as follows: $50 \%$ Mexican-American, $35 \%$ white, and $15 \%$ black. The serum was withdrawn and stored at $-40^{\circ} \mathrm{C}$ until assay.

Serum samples were tested for the presence of precipitating antibodies to SS-A and SS-B antigens using double immunodiffusion techniques. ${ }^{14}$ The source of antigens was calf thymic extract supplied by Alpha Antigens Inc. Serum samples with precipitating antibodies were compared with reference samples known to contain precipitating antibodies to either SS-A or SS-B antigens as controls. Antinuclear antibody testing using the immunofluorescent technique on human epithelial cells (HEp-2 cells) was performed on the samples from motherinfant pairs who were positive for SS-A antibodies.

\section{Results}

Four maternal (1.3\%) and four cord (1.3\%) samples contained the SS-A antibody. Of these, three maternal and three infant samples belonged to matched mother-infant pairs. The other two positive sera were from one mother with an infant negative for SS-A antibodies and from one infant with a negative mother.

On review of hospital records of the isolated, unmatched positive pairs no evidence of manifestations of connective tissue disease or neonatal lupus syndrome was found in mother and infant respectively. Follow up on these patients was not available. The three SS-A positive mothers, who each delivered one infant also positive for SS-A anti- 
Table $1 S S-A$ antibody positive mother-infant pairs

\begin{tabular}{llllll}
\hline Pair & SS- $\boldsymbol{A}$ & SS- $\boldsymbol{B}$ & ANA & $\begin{array}{l}\text { History of clinical } \\
\text { disease at birth }\end{array}$ & $\begin{array}{l}\text { History of clinical } \\
\text { disease at follow up }\end{array}$ \\
\hline $\begin{array}{l}\text { Mother } \\
\text { Infant }\end{array}$ & + & - & - & Negative & Negative \\
Mother & + & - & - & Negative & Negative \\
Infant & + & - & - & Negative & Negative \\
Mother & + & - & $+(1 / 40)$ & Negative & Negative \\
Infant & + & - & $+(1 / 40)$ & Negative & Not available \\
\hline
\end{tabular}

ANA $=$ antinuclear antibody.

bodies, had no evidence of a history or current manifestations of connective tissue disease and no evidence of current infection. Likewise, each of their respective infants had no evidence of neonatal lupus syndrome during their stay in hospital in the immediate postpartum period.

Two of the three SS-A antibody positive motherinfant pairs were available for follow up about two and a half months after birth. Neither mother presented with any evidence of connective tissue disease and neither infant presented with any manifestation of the neonatal lupus syndrome. Both infants had normal electrocardiograms without evidence of any heart block (Table 1).

Antinuclear antibody testing performed on all SS-A antibody positive mother-infant pairs showed one pair with both negative, one pair in which the mother was negative and the infant was antinuclear antibody positive ( $1 / 40$ homogeneous) and one pair in which both were antinuclear antibody positive (1/40 homogeneous).

Of the $\mathbf{3 0 0}$ maternal samples tested, only one was positive for SS-B antibodies. There were no SS-B antibody positive infants in the 300 infant samples tested.

\section{Discussion}

Neonatal lupus syndrome usually develops between birth and three months of age. Usually, the presentation is characterised by cutaneous lesions of erythema annulare, which often manifests as a photosensitive reaction. Erythematous cutaneous lesions in infants have been reported to be associated with a maternal autoimmune disease since 1954.' Hammer $^{3}$ reported three infants with erythema annulare centrifugum whose mothers all had documented or suspected diagnoses of systemic lupus erythematosus. Several studies since have documented the frequent association of SS-A antibodies in mothers whose infants developed the neonatal lupus syndrome. ${ }^{8-10}$ Most of these studies have suggested transplacental passage of the IgG antibodies as a possible cause.
Congenital heart block may occur in conjunction with other manifestations of the neonatal lupus syndrome or as an isolated finding. ${ }^{5-7}$ Similarly, studies have linked the association of the SS-A antibody to congenital heart block in infants with the syndrome. $^{1213}$ SS-A antibody has recently been detected in $83 \%$ of mothers of infants with isolated congenital heart block. ${ }^{13}$ In the same study, the antibody was present in seven of eight infants with isolated congenital heart block when their serum was tested before three months of age.

A previous study of 50 normal mother-infant pairs found no positive individuals for the SS-A antibody..$^{13}$ Weston et al ${ }^{11}$ likewise studied 71 infants from birth to five months of age, of whom 45 were healthy and the others had various reactive erythemas. All 71 of their subjects were negative for SS-A and SS-B antibodies (Table 2).

In our study 300 randomly selected mother-infant pairs were tested for SS-A and SS-B antibodies. Three $(1 \%)$ of the 300 mother-infant pairs were positive for SS-A antibody but we found no evidence of autoimmune disease or neonatal lupus syndrome in the mothers or infants respectively at the time of birth. Further, no disease activity was ascertained in the two mother-infant pairs available for follow up two and a half months after birth.

The presence of antibody in pairs may represent some antibody cross reactivity with the SS-A antigen, which is also transplacentally passed to the infant. If, however, it in fact represents true SS-A antibody positivity, which may occur in mothers who are asymptomatic for connective tissue disease, then one must either question the aetiological nature of the antibody in producing the neonatal lupus syndrome or assume that an additional, unknown factor determines susceptability or expression. Some significant titre of antibody may be necessary for disease expression and further prospective analysis using data on antibody titre should be performed. The SS-A antibody may serve as a marker or be a consequence of the disease processes without being the actual cause of the disease. Of interest is the recent finding of an unusual prevalence of the SS-A 
Table 2 Summary of reported random control sera tested for $S S-A$ and $S S-B$ antibodies

\begin{tabular}{llll}
\hline & No & \multicolumn{2}{l}{ Positive for } \\
\cline { 3 - 4 } & & $S S-A$ & $S S-B$ \\
\hline Weston et $^{\prime \prime \prime}$ & 71 infants & 0 & 0 \\
Scott et $^{13}{ }^{\prime 3}$ & 50 mothers* & 0 & 0 \\
Present study & 50 infants & 0 & 0 \\
& 300 mothers* & 4 & 1 \\
& 300 infants & 4 & 0 \\
\hline
\end{tabular}

*Matched mother-infant pairs

(Ro) antibody in homozygous $\mathrm{C}_{2}$ deficiency associated with systemic lupus erythematosus like illness. ${ }^{15}$ Previous reports of neonatal lupus syndrome have not included data on complement component levels. From the studies available, the data do not appear to confirm nor disprove the proposed aetiological link between the presence of SS-A antibodies and the neonatal lupus syndrome.

Certainly, more studies are needed to evaluate the efficacy of random maternal screening for the presence of SS-A antibodies. Perhaps measurements of simultaneous serial complement components, especially $C_{2}$, would be useful in patients positive for the SS-A antibody. Our study suggests that any predictive nature of SS-A antibody is doubtful, and SS-A antibody testing would appear not to be cost effective as a mass screening procedure in the detection of infants with the potential to develop neonatal lupus syndrome.

\section{References}

' McCuiston CH, Schoch EP. Possible discoid lupus erythematosus in newborn infants. Arch Dermatol 1954;70:782-5.
2 Vonderheid EC, Koblenzer PJ, Ming PML, Burgoon CF. Neonatal lupus erythematosus. Arch Dermatol 1976;112:698-705.

${ }^{3}$ Hammar H, Ronnerfalt L. Annular erythemas in infants associated with autoimmune disorders in their mothers. Dermatology 1977; 154:115-27.

4 Bremers HH, Golitz LE, Weston WL, Hays WG. Neonatal lupus erythematosus. Cutis 1979; 24:287-90.

${ }^{5}$ Chameides L, Truex RC, Vetter V, Rashkind WJ, Galioto FM, Noonan JA. Association of maternal systemic lupus erythematosus with congenital complete heart block. $N$ Engl J Med 1977;297: 1204-7.

- McCue CM, Mantakas ME, Tingelstad JB, Ruddy S. Congenital heart block in newborns of mothers with connective tissue disease. Circulation 1977; 56:82-90.

${ }^{7}$ Esscher E, Scott JS. Congenital heart block and maternal systemic lupus erythematosus. $\mathrm{Br}$ Med J 1979; i: 1235-8.

${ }^{8}$ Kephart DC, Hood AF, Provost TT. Neonatal lupus erythematosus: new serologic findings. J Invest Dermatol 1981;77:331-3.

' Miyagawa S, Kitamura W, Yoshioka J, Sakamoto K. Placental transfer of anticytoplasmic antibodies in annular erythema of newborns. Arch Dermatol 1981; 117:569-72.

${ }^{10}$ Franco HL, Weston WL, Peebles C, Forstot SL, Phanuphak P. Antibodies directed against sicca syndrome antigens in the neonatal lupus syndrome. J Am Acad Dermatol 1981;4:67-72.

"Weston WL, Harmon C, Pebbles C, et al. A serological marker for neonatal erythematosus. $B J$ Dermatol 1982;107:377-82.

12 Reed BR, Lee LA, Harmon C, et al. Autoantibodies to SS-A/Ro in infants with congenital heart block. J Pediatr 1983; 103: 889-91.

${ }^{13}$ Scott JS, Maddison PJ, Taylor PV, Esscher E, Scott O, Skinner RP. Connective tissue disease, antibodies to ribonucleoprotein, and congenital heart block. $N$ Engl $J$ Med 1983;309:209-12.

${ }^{14}$ Alspaugh MA, Talal N, Tan EM. Differentiation and characterization of autoantibodies and their antigens in Sjogren's syndrome. Arth Rheum 1976;19:216-22.

15 Provost TT, Arnett FC, Reichlen M. Homozygous $\mathrm{C}_{2}$ deficiency, lupus erythematosus, and anti-Ro (SSA) antibodies. Arth Rheum 1983;26:1279-82.

Requests for reprints to: Dr Michael Calmes, Texas Tech University Health Sciences Center, School of Medicine, Lubbock, Texas 79430, USA. 